\title{
Role of Serum Leptin in the Diagnosis and Prognosis of Hepatocellular Carcinoma in Egyptian Cirrhotic Patients
}

\author{
MOHAMED M. SALAMA, M.D. ${ }^{\mathbf{1}}$; AHMED S. ALLAM, M.D. ${ }^{\mathbf{1}}$; HAYTHAM M. NASSER, M.D. ${ }^{\mathbf{2}}$; \\ WALAA A. YOUSRY KABIEL, M.D. ${ }^{3}$ and EHAB H. ELSAYED, M.D. ${ }^{4}$ \\ The Departments of Internal Medicine ${ }^{1}$, Radiology ${ }^{2}$ and Clinical Pathology ${ }^{3}$, Faculty of Medicine, Ain Shams University and \\ The Department of Tropical Medicine, National Research Center ${ }^{4}$, Cairo, Egypt
}

\begin{abstract}
Background: Hepatocellular carcinoma is the most common primary hepatic malignancy with an average survival rate of 6-20 months. The primary etiology of hepatocellular carcinoma in Egyptian patients is liver cirrhosis. Alfa fetoprotein is the most commonly used biomarker for HCC diagnosis, in spite of its low sensitivity and specificity in HCC screening; it is usually combined with ultrasound for early detection of HCC. Leptin is a multifunctional peptide hormone that is produced by adipocytes with neuroendocrine activity. Leptin is postulated to increase the hepatic response to different stimuli of liver fibrosis. The actions of leptin are mediated via hepatic stellate cell activation, and liver fibrosis occurs through its indirect effect on the Kupffer cells. Moreover, it regulates the phosphoinositide 3-kinase/protein kinase B (PI$3 \mathrm{~K} / \mathrm{Pkt}$ ) pathway, which plays an essential step in the cell motility, proliferation, survival, and angiogenesis in tumor cells including Hepatocellular Carcinoma (HCC). Thus, leptin can promote HCC proliferation, migration, and invasion.
\end{abstract}

Aim of Study: The present study aimed to evaluate the diagnostic and prognostic value of serum Leptin as a tumor marker in Hepatocellular Carcinoma (HCC) in comparison to Alpha-Fetoprotein (AFP).

Subjects and Methods: This study included 180 Egyptian patients that were divided into 4 groups (Group 1: 60 patients with untreated HCC, Group 2: 60 patients with treated HCC, Group 3: 30 patients with end-stage chronic liver disease without HCC) in addition to Group 4: 30 age-matched healthy subjects serving as a healthy control group. All patients and controls were subjected to full history, clinical examination, laboratory investigation, and abdominal ultrasonography (U/S). Serum leptin and alpha-fetoprotein were assayed by using Enzyme-Linked Immunosorbent Assay (ELISA) technique.

Results: The results of the present study revealed that serum leptin levels were significantly increased in all the patients' groups when compared to controls; besides, it was significantly higher in untreated and treated HCC patients groups when compared to patient's group without HCC.

Correspondence to: Dr. Ahmed S. Allam, E-Mail: ahm82allam@gmail.com
Furthermore, serum leptin levels were significantly higher in the patients group with untreated HCC compared to the treated HCC patients group with positive correlation with AFP.

Conclusion: AFP was more sensitive and specific in differentiation between cirrhotic patients with or without HCC than Leptin. However, Leptin has a good sensitivity and specificity in differentiating between untreated and treated HCC patients, and it is superior to AFP in the specificity of the differentiation between these two categories.

Therefore, serum leptin can be used as a useful screening marker for the diagnosis and prognosis of HCC patients combined with Alfa fetoprotein.

Key Words: leptin-AFP - Liver cirrhosis - Hepatocellular carcinoma.

\section{Introduction}

HEPATOCELLULAR Carcinoma (HCC) is the most frequent primary liver malignancy, with an

\begin{tabular}{ll}
\hline List of Abbreviations: \\
AFP & : Alpha Feto Protien. \\
ALT & : Alanine Aminotransferase. \\
AST & : Aspartate Aminotransferase. \\
CBC & : Complete Blood Count. \\
FBG & : Fasting Blood Glucose. \\
Hb & : Hemoglobin. \\
HCC & : Hepatocellular Carcinoma. \\
HCV & : Hepatitis C Virus. \\
HBV & : Hepatitis B Virus. \\
HFL & : Hepatic Focal Lesions. \\
INR & : International Normalized Ratio \\
NAFLD & : Non-Alcoholic Fatty Liver Disease. \\
NASH & : Non-Alcoholic Steatohepatitis. \\
PI-3K/Pkt & Phosphoinositide 3-Kinase/Protein Kinase B. \\
TGF-B & : Transforming Growth Factor B. \\
TPCT & : Triphasic CT. \\
U/S & : Ultrasound. \\
VEGF & : Vascular Endothelial Growth Factor. \\
WBCs & : White Blood Cells. \\
WHO & : World Health Organization.
\end{tabular}


average survival rate between 6 to 20 months. Additionally, it is the fifth most prevalent malignancy and the second most frequent global cause of cancer-related mortality rates [1].

Liver cirrhosis usually occurs as a result of; chronic hepatitis $\mathrm{C}$ infection, hepatitis B infection, alcoholic liver disease, and Non-Alcoholic Fatty Liver Disease (NAFLD). HCC usually occurs on top of liver cirrhosis [2]. Early diagnosis of HCC is of great importance in improving the survival rates; thus, a surveillance program is essential for early diagnosis [3].

Current guidelines recommend abdominal ultrasound for HCC screening [4]. The ultrasound (U/S) sensitivity differs as it is an operatordependent; besides, its use would be limited by the tumor location and difficult patient characteristics as obesity and advanced liver cirrhosis. Therefore, other tools have been proposed to increase the HCC identification rates. Serum AFP is the most frequently used, but the benefit is controversial. Current American and European guidelines do not recommend serum AFP for HCC surveillance due to cost-benefit issues [5] .

Leptin is a hormone that is produced by adipose cells. It helps in regulating the energy balance through inhibiting hunger sensation as it acts on receptors in the arcuate nucleus of the hypothalamus. Additionally, it plays an essential role in regulating the neuroendocrine, immune functions, glucose, lipid, and bone metabolism [6].

Leptin plays a fibrogenic role in the liver through stimulation of type I procollagen expression and potentiation of Transforming Growth Factor B (TGF-B) actions that cease collagen degradation. Moreover, it stimulates the induction of Vascular Endothelial Growth Factor (VEGF) via oxygenindependent activation of hypoxia-inducible factor $1 \mathrm{a}$, an essential step in the angiogenic response $\left[{ }^{7}\right]$.

In addition, leptin plays a vital role in neoplasia as it regulates the phosphoinositide 3-kinase/protein kinase B (PI-3K/Pkt), which plays a central role in a variety of multiple biological processes such as cell motility, proliferation, survival, and angiogenesis in tumor cells including HCC. Thus, Leptin can promote HCC proliferation, migration, and invasion [8]

\section{Aim of the work:}

The aim of the present study was to assess the diagnostic and prognostic value of serum leptin as a tumor marker in Hepatocellular Carcinoma (HCC) in comparison to Alphafetoprotein (AFP).

\section{Material and Methods}

This was a case-control study that was conducted on 180 subjects who were recruited from the in-patient ward and the outpatient clinic of the Internal Medicine Department of Ain Shams University Hospitals from the period of October 2017 to September 2018.

Informed written consent was obtained from each participant before enrolment in the study.

Moreover, the study was approved by the Research Ethics Committee of Ain Shams University.

Subjects were classified into four groups; Group 1: Included 60 cirrhotic patients with HCC without previous therapeutic intervention with confirmed diagnosis of HCC by Triphasic CT abdomen. Group 2: Included 60 cirrhotic patients with HCC with previous therapeutic intervention six months after intervention with no recurrence on the Triphasic CT abdomen. Group 3: Included 30 patients with end-stage chronic liver disease patients without HCC. All patients groups were post HCV end stage-liver disease. Group 4: Included 30 healthy subjects serving as controls. They were blood donors or relatives of patients from the outpatient clinic. Patients with age less than 18 years old, diabetics, drug abusers, patients with renal impairment, and HBV infection were excluded from the study.

Full history was taken from all individuals included in the study with a thorough clinical examination with particular emphasis on the stigmata of chronic liver disease including jaundice, spider naevi, ascites, splenomegaly, palmer erythema, and lower limb edema. All participants in this study were subjected to complete blood picture, liver function tests: Serum alanine and aspartate amino-transferases (ALT and AST respectively), serum bilirubin (total and direct), serum albumin, prothrombin time, Gamma-Glutamyl Transferase (GGT), serum alkaline phosphatase, serum creatinine, blood urea, and fasting blood sugar in addition to viral markers $\mathrm{HCV} \mathrm{Ab}, \mathrm{HBsAg}$, and $\mathrm{HBcIgG}$ by Enzyme-Linked Immunosorbent Assay (ELISA) technique. Abdominal ultrasonography was done for all subjects for diagnosis of the liver cirrhosis and hepatic focal lesions. Triphasic CT and alphafetoprotein were used to confirm the diagnosis of HCC. In addition, measurement of serum leptin levels and alpha-fetoprotein using the Enzyme- 
Linked Immunosorbent Assay (ELISA) technique according to the manufacturer's instructions were done.

Four milliliters $(4 \mathrm{~mL})$ of blood were collected in a sterile plain vacutainer and were left to clot for 30 minutes. The serum was separated by centrifugation at $3000 \mathrm{rpm}$ for 10 minutes. The separated serum was stored at $20^{\circ} \mathrm{C}$ until the assay of serum leptin.

Serum leptin levels were measured using the commercial Enzyme-Linked Immunosorbent Assay (ELISA) kit supplied by Diagnostics Biochem Canada (DBC) Company. The principle of the kit follows a typical two-step capture or sandwich type assay. A standard curve was constructed from which the concentrations of leptin in the patient samples and controls were directly read.

\section{Statistical analysis:}

Data were analyzed using IBM $\odot$ SPSS $\odot$ Statistics version 23 (IBM@ C Corp., Armonk, NY, USA) and MedCalc $\odot$ version 18.2.1 (MedCalc $\odot$ Software bvba, Ostend, Belgium). Normally distributed numerical data were presented as mean and standard deviation, and intergroup differences were compared using one-way analysis of variance (ANOVA) with application of the Tukey-Kramer test for post-hoc pairwise comparisons if needed. Non-normally distributed numerical data were presented as median and Interquartile Range (IQR), and between-group differences were compared using the Kruskal-Wallis test with the application of the Dunn test for post-hoc pairwise comparisons if needed.

Categorical data were presented as number and percentage, and intergroup differences were compared using Fisher's exact test or the chi-squared test for trend (for ranked data).

\section{Results}

This study included 180 patients who were divided into four groups. Group 1 included 60 HCC patients without previous therapeutic intervention. Group 2: Included $60 \mathrm{HCC}$ patients with previous therapeutic intervention. Group 3: Included 30 patients with end-stage chronic liver disease patients without HCC and Group 4: Included 30 healthy subjects serving as controls.

Table (1) showed that there was no significant difference between the studied groups regarding sex and age.
Table (2) shows that there was no difference between groups as regards TLC, and FBS. All patients groups were significantly higher as regards ALT, AST, Bilirubin, and PT compared to the control group. The patient groups were significantly lower as regard hemoglobin, platelet count, and albumin than normal controls $(p<0.01)$.

Table (3) showed that the HCC untreated and treated groups (Group 1and 2) were significantly higher as regards AFP than group 3 (CLD without HCC). Group1 (untreated HCC) was significantly higher as regards AFP than group 2 (treated HCC).

Moreover, as regards serum AFP levels, all patients groups (1,2 and 3$)$ were significantly higher than the control group (4) $(p<0.01)$. Serum leptin levels were significantly higher in the HCC groups ( 1 and 2) than in group 3 (CLD without HCC). Moreover, the serum leptin levels in untreated HCC (group1) was significantly higher than treated HCC (group2) $(p<0.01)$ as shown in (Table 3) and Fig. (1).

Fig. (1) box plot showing serum leptin level in the four study groups. Box represents the range from the 1 st to 3 rd quartile (interquartile range). Line inside the box represents the median (2 nd quartile). Whiskers represent the minimum and maximum values excluding outliers and extreme values.

Table (4) and Fig. (2) show the good performance of leptin in discrimination between CLD patients with or without $\mathrm{HCC}$ with $p$-value $<0.0001$, cut off $>3.5 \mathrm{ng} / \mathrm{ml}$, sensitivity $=85 \%$, specificity $=$ $80 \%$ ) but AFP still superior to it in this discrimination by sensitivity $=98.3 \%$, specificity $=93.3 \%$.

Table (5) and Fig. (3) showed the good performance of leptin in discrimination between untreated and treated HCC patients with $p$-value $<0.0001$, cut off $>20 \mathrm{ng} / \mathrm{ml}$, sensitivity $=93.3 \%$, specificity $=93.3 \%$. Although AFP has better sensitivity than leptin in this discrimination, leptin is superior to it by specificity $=93.3 \%$.

Table (6) showed the correlation between serum leptin levels and all the quantitative variables.

There was a high statistical significant difference observed between serum leptin levels and platelet count, serum total bilirubin, serum albumin levels, and prothrombin time. Moreover, a statistically significant difference was observed between serum leptin levels and age, TLC, serum ALT, AST, direct bilirubin, and fasting blood sugar. 
Table (1): Demographic characteristics of the four study groups.

\begin{tabular}{lcccccc}
\hline & $\begin{array}{c}\text { Group 1 } \\
(\mathrm{n}=60)\end{array}$ & $\begin{array}{c}\text { Group 2 } \\
(\mathrm{n}=60)\end{array}$ & $\begin{array}{c}\text { Group 3 } \\
(\mathrm{n}=30)\end{array}$ & $\begin{array}{c}\text { Group 4 } \\
(\mathrm{n}=30)\end{array}$ & $\begin{array}{c}\mathrm{F} \\
(3,87)\end{array}$ & $\begin{array}{c}p \text { - } \\
\text { value }\end{array}$ \\
\hline Age $(\mathrm{yr})$ & $56 \pm 6 \dagger$ & $54 \pm 5 \dagger$ & $54 \pm 8 \dagger$ & $47 \pm 10$ & 30.386 & $<0.274^{*}$ \\
Gender $(\mathrm{M} / \mathrm{F})$ & $46 / 14$ & $42 / 18$ & $18 / 12$ & $16 / 14$ & - & $0.383 \#$ \\
\hline Data are mean \pm standard deviation or ratio. & & & \\
$\mathrm{F}$ & $:$ F statistic. \\
$*$ & : One-way analysis of variance (ANOVA). & & \\
$\#$ & : Fisher's exact test. \\
$\dagger$ & : Statistically significant difference versus normal control (Tukey-Kramer test). \\
Group 1 & : Cirrhotic patients with HCC without previous therapeutic intervention. \\
Group 2 : Cirrhotic patients with HCC with previous therapeutic intervention. & \\
Group 3 & : End-stage chronic liver disease patients without HCC. \\
Group 4 & : Controls.
\end{tabular}

Table (2): Descriptive data of all groups and the statistical comparison between them.

\begin{tabular}{|c|c|c|c|c|c|c|c|c|c|c|}
\hline \multirow{2}{*}{ Variable } & \multicolumn{2}{|c|}{$\begin{array}{l}\text { Group } 1 \\
(n=60)\end{array}$} & \multicolumn{2}{|c|}{$\begin{array}{l}\text { Group } 2 \\
(n=60)\end{array}$} & \multicolumn{2}{|c|}{$\begin{array}{c}\text { Group } 3 \\
(n=30)\end{array}$} & \multicolumn{2}{|c|}{$\begin{array}{c}\text { Group } 4 \\
(n=30)\end{array}$} & \multirow{2}{*}{$\begin{array}{c}F \\
(3,87)\end{array}$} & \multirow{2}{*}{$\begin{array}{c}p- \\
\text { value* }\end{array}$} \\
\hline & Mean & SD & Mean & SD & Mean & SD & Mean & SD & & \\
\hline $\operatorname{TLC}\left(/ \mathrm{mm}^{3}\right)$ & 5.9 & 2.5 & 6.8 & 2.0 & 5.9 & 2.0 & 7.6 & 1.3 & 2.769 & 0.047 \\
\hline Hemoglobin (g/dl) & $10.4 \dagger$ & 1.4 & $9.9 \dagger$ & 1.0 & $10.8 \dagger$ & 1.8 & 13.5 & 1.7 & 22.441 & $<0.001$ \\
\hline Platelets $\left(\mathrm{k} / \mathrm{mm}^{3}\right)$ & $69+$ & 24 & $77+$ & 26 & $84 \dagger$ & 64 & 244 & 53 & 77.106 & $<0.001$ \\
\hline ALT (IU/1) & $54 \uparrow \S$ & 15 & $70 \uparrow$ & 19 & $61 \dagger$ & 20 & 17 & 5 & 36.080 & $<0.001$ \\
\hline AST (IU/1) & $48+\S$ & 13 & $64 \uparrow$ & 17 & $56 \dagger$ & 18 & 17 & 5 & 36.320 & $<0.001$ \\
\hline Total bilirubin (mg/dl) & $2.5 \dagger$ & 0.6 & $2.5 \dagger$ & 0.6 & $2.5 \dagger$ & 0.6 & 1.0 & 0.1 & 29.930 & $<0.001$ \\
\hline Serum albumin (g/dl) & $2.5 \dagger$ & 0.4 & $2.6 \dagger$ & 0.3 & $2.6 \dagger$ & 0.5 & 4.4 & 0.5 & 85.804 & $<0.001$ \\
\hline PT (s) & $17+t$ & 2 & $17 \dagger$ & 3 & $15 \dagger$ & 3 & 12 & 1 & 21.829 & $<0.001$ \\
\hline FBS (mg/dl) & 94 & 8 & 96 & 9 & 98 & 10 & 99 & 9 & 1.561 & 0.205 \\
\hline
\end{tabular}

Data are mean and standard deviation (SD).

F : F statistic.

: One-way analysis of variance (ANOVA).

: Statistically significant difference versus normal control (Tukey-Kramer test).

Statistically significant difference versus end-stage CLD without HCC (Tukey-Kramer test).

: Statistically significant difference versus treated HCC (Tukey-Kramer test).

Group 1 : Cirrhotic patients with HCC without previous therapeutic intervention.

Group 2 : Cirrhotic patients with HCC with previous therapeutic intervention.

Group 3 : End-stage chronic liver disease patients without HCC.

Group 4 : Controls.

TLC : Total Leucocytic Count.

ALT : Alanine Aminotransferase.

AST : Aspartate Aminotransferase.

PT : Prothrombin Time.

GGT : Gamma Glutamyl Transferase.

ALP : Alkaline Phosphatase.

FBS : Fasting Blood Sugar.

Table (3): Comparison of serum leptin and alpha-fetoprotein in the four study groups.

\begin{tabular}{|c|c|c|c|c|c|c|c|c|c|c|}
\hline \multirow[t]{2}{*}{ Variable } & \multicolumn{2}{|c|}{$\begin{array}{c}\text { Group } 1 \\
(\mathrm{n}=60)\end{array}$} & \multicolumn{2}{|c|}{$\begin{array}{c}\text { Group } 2 \\
(n=60)\end{array}$} & \multicolumn{2}{|c|}{$\begin{array}{c}\text { Group } 3 \\
(\mathrm{n}=30)\end{array}$} & \multicolumn{2}{|c|}{$\begin{array}{c}\text { Group } 4 \\
(n=30)\end{array}$} & \multirow[t]{2}{*}{ Ht (3) } & \multirow{2}{*}{$\begin{array}{c}p- \\
\text { value* }\end{array}$} \\
\hline & Med. & IQR & Med. & IQR & Med. & IQR & Med. & IQR & & \\
\hline Alphafetoprotein (ng/ml) & $138+\hbar \S$ & $100-244$ & $45+\div$ & $58-58$ & 10 & $7-14$ & 4 & $2-5$ & 77.482 & $<0.0001$ \\
\hline Serum leptin (ng/ml) & $40 \dagger \div \S$ & $37-50$ & $8 \dagger$ & $3-20$ & 2 & $1-4$ & 1 & $1-1$ & 67.865 & $<0.0001$ \\
\hline
\end{tabular}

Data are median (Med.) and interquartile range (IQR).

Ht: Kruskal-Wallis statistic.

*: Kruskal-Wallis test.

$\dagger$ : Statistically significant difference versus normal control (Dunn test).

†: Statistically significant difference versus end-stage CLD without HCC (Dunn tesso, $\mathrm{t}$ )

$\S$ : Statistically significant difference versus treated HCC (Dunn test).

Group 1: Cirrhotic patients with HCC without previous therapeutic intervention.

Group 2: Cirrhotic patients with HCC with previous therapeutic intervention.

Group 3: End-stage chronic liver disease patients without HCC.

Group 4: Controls. 
Table (4): Receiver-Operating Characteristic (ROC) curve analysis for discrimination between CLD patients with or without HCC.

\begin{tabular}{|c|c|c|}
\hline \multirow[t]{3}{*}{$\begin{array}{l}\text { Sample size } \\
\text { Positive group (HCC) } \\
\text { Negative group (No H } \\
\text { Disease prevalence }(\%\end{array}$} & \multicolumn{2}{|c|}{$\begin{array}{l}150 \\
120(80.0 \%) \\
30(20.0 \%) \\
80 \%\end{array}$} \\
\hline & \multicolumn{2}{|c|}{ Marker } \\
\hline & Leptin & AFP \\
\hline $\begin{array}{l}\text { - Area under the ROC curve } \\
\text { (AUC) }\end{array}$ & 0.909 & 0.980 \\
\hline - Standard Error & 0.040 & 0.016 \\
\hline - $95 \%$ Confidence interval & 0.820 to 0.963 & 0.917 to 0.999 \\
\hline - Z statistic & $\begin{array}{l}10.278 \\
<0.0001\end{array}$ & $\begin{array}{l}30.606 \\
<0.0001\end{array}$ \\
\hline - Youden index J & 0.650 & 0.917 \\
\hline - Cut-off criterion & $>3.5 \mathrm{ng} / \mathrm{ml}$ & $>16 \mathrm{ng} / \mathrm{ml}$ \\
\hline - Sensitivity, \% & 85.0 & \\
\hline$\bullet 95 \%$ CI & 73.4-92.9 & $91.1-100.0$ \\
\hline - Specificity, \% & & 93.3 \\
\hline $\begin{array}{l}\text { Positive likelihood ratio } \\
\text { (+LR) }\end{array}$ & $\begin{array}{l}51.9-95.7 \\
4.25\end{array}$ & $\begin{array}{l}68.1-99.8 \\
14.75\end{array}$ \\
\hline - $95 \%$ CI & $1.5-11.8$ & $2.2-98.0$ \\
\hline $\begin{array}{l}\text { - Negative likelihood ratio } \\
(-\mathrm{LR})\end{array}$ & 0.19 & 0.018 \\
\hline - $95 \% \mathrm{CI}$ & $0.10-0.4$ & $0.003-0.1$ \\
\hline $\begin{array}{l}\text { - Positive predictive value } \\
(+\mathrm{PV}), \%\end{array}$ & 94.4 & 98.3 \\
\hline$\bullet 95 \%$ CI & $86.0-97.9$ & 89.9-99.7 \\
\hline $\begin{array}{l}\text { - Negative predictive value } \\
(-\mathrm{PV}),\end{array}$ & 57.1 & 93.3 \\
\hline - $95 \% \mathrm{CI}$ & $41.0-71.9$ & $66.6-99.0$ \\
\hline
\end{tabular}

Table (5): Receiver-Operating Characteristic (ROC) curve analysis for discrimination between patients with untreated or treated HCC.

\begin{tabular}{|c|c|c|}
\hline \multirow[t]{3}{*}{$\begin{array}{l}\text { Sample size } \\
\text { Positive group (untreated } \\
\text { Negative group (treated } \\
\text { Disease prevalence }(\%)\end{array}$} & $\begin{array}{l}\mathrm{HCC}) \\
{[\mathrm{CC})}\end{array}$ & $\begin{array}{l}120 \\
60(50.0 \%) \\
60(50.0 \%) \\
50\end{array}$ \\
\hline & \multicolumn{2}{|c|}{ Marker } \\
\hline & Leptin & AFP \\
\hline $\begin{array}{l}\text {-Area under the ROC curve } \\
\text { (AUC) }\end{array}$ & 0.944 & 0.986 \\
\hline - Standard Error & 0.032 & 0.010 \\
\hline - $95 \%$ Confidence interval & 0.852 to 0.987 & 0.914 to 1.000 \\
\hline $\begin{array}{l}\cdot \mathrm{Z} \text { statistic } \\
\cdot p \text {-value }(\mathrm{AUC}=0.5)\end{array}$ & $\begin{array}{l}13.909 \\
<0.0001\end{array}$ & $\begin{array}{l}48.422 \\
<0.0001\end{array}$ \\
\hline - Youden index $\mathbf{J}$ & 0.867 & 0.867 \\
\hline - Cut-off criterion & $>20 \mathrm{ng} / \mathrm{ml}$ & $>72 \mathrm{ng} / \mathrm{ml}$ \\
\hline $\begin{array}{l}\text { - Sensitivity, \% } \\
\text { - } 95 \% \text { CI }\end{array}$ & 93.3 & 96.7 \\
\hline - Specificity, \% & 93.33 & $\begin{array}{l}02.0-99.9 \\
90\end{array}$ \\
\hline - $95 \%$ CI & $77.9-99.2$ & $73.5-97.9$ \\
\hline $\begin{array}{l}\text { - Positive likelihood ratio } \\
(+\mathrm{LR})\end{array}$ & 14 & 9.67 \\
\hline - $95 \% \mathrm{CI}$ & $3.7-53.6$ & $3.3-28.3$ \\
\hline $\begin{array}{l}\text { - Negative likelihood ratio } \\
(-\mathrm{LR})\end{array}$ & 0.071 & 0.037 \\
\hline - $95 \% \mathrm{CI}$ & $0.02-0.3$ & $0.005-0.3$ \\
\hline $\begin{array}{l}\text { - Positive predictive value } \\
(+\mathrm{PV}), \%\end{array}$ & 93.3 & 90.6 \\
\hline - $95 \% \mathrm{CI}$ & $78.5-98.2$ & $76.7-96.6$ \\
\hline $\begin{array}{l}\cdot \text { Negative predictive value } \\
(-\mathrm{PV}) \text {, }\end{array}$ & 93.3 & 96. \\
\hline - $95 \%$ CI & $78.5-98.2$ & $79.7-99.5$ \\
\hline
\end{tabular}

Table (6): Correlation between serum leptin and other quantitative variables.

\begin{tabular}{lcc}
\hline \multirow{2}{*}{ Variable } & \multicolumn{2}{c}{ Serum leptin } \\
\cline { 2 - 3 } & Spearman's rho & $p$-value \\
\hline Age & $0.309^{* *}$ & 0.003 \\
TLC & $-0.274^{* *}$ & 0.009 \\
Hemoglobin & $-0.279^{*}$ & 0.008 \\
Platelets & $-0.459^{* *}$ & $<0.001$ \\
ALT & $0.246^{*}$ & 0.019 \\
AST & $0.243^{*}$ & 0.021 \\
Total bilirubin & $0.362^{* *}$ & $<0.001$ \\
Serum albumin & $-0.493^{* *}$ & $<0.001$ \\
PT & $0.420^{* *}$ & $<0.001$ \\
FBS & $-0.280^{* *}$ & 0.007 \\
\hline
\end{tabular}

* : Correlation is significant at the 0.05 level (2-tailed).

: Correlation is significant at the 0.01 level (2-tailed).

TLC : Total Leucocytic Count.

ALT : Alanine Aminotransferase.

AST : Aspartate Aminotransferase.

PT : Prothrombin Time.

GGT : Gamma Glutamyl Transferase.

ALP : Alkaline Phosphatase.

FBS : Fasting Blood Sugar.

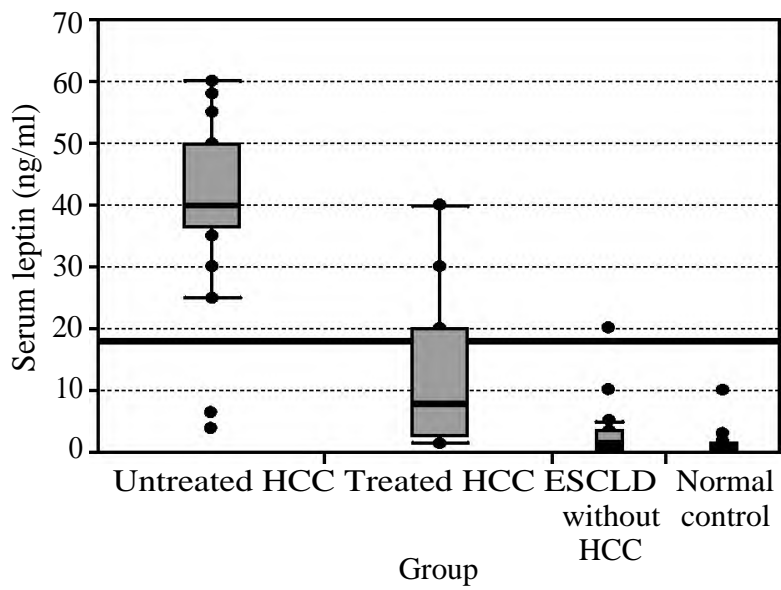

Fig. (1): Comparison between groups as regard leptin level.

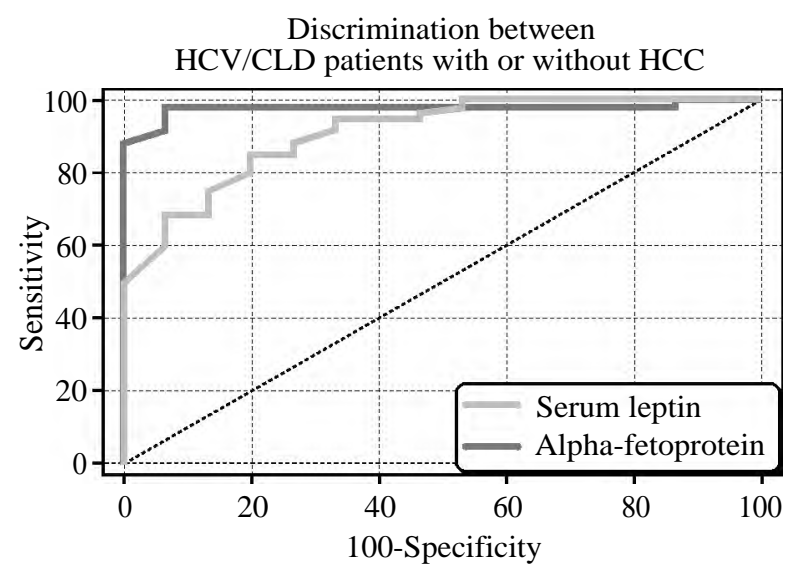

Fig. (2): Receiver-Operating Characteristic (ROC) curve for discrimination between CLD patients with or withou HCC using serum leptin (AUC $=0.909$, cutoff $>3.5 \mathrm{ng} / \mathrm{ml}$, sensitivity $=85 \%$, specificity $=80 \%$ ) or AFP (AUC $=0.980$, cutoff $>16 \mathrm{ng} / \mathrm{ml}$, sensitivity $=98.3 \%$, specificity $=93.3 \%$ ). 


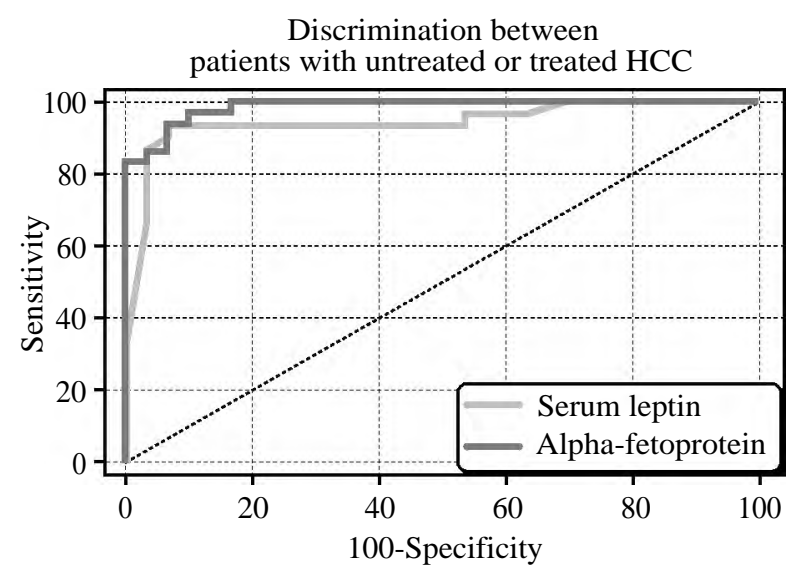

Fig. (3): Receiver-Operating Characteristic (ROC) curve for discrimination between patients with untreated or treated HCC using serum leptin (AUC $=0.944$, cutoff $>20 \mathrm{ng} / \mathrm{ml}$, sensitivity $=93.3 \%$, specificity $=93.3 \%)$ or AFP $($ AUC $=0.986$, cutoff $>72 \mathrm{ng} / \mathrm{ml}$, sensitivity $=96.7 \%$, specificity $=90 \%$ ).

\section{Discussion}

More than eighty percent of hepatic malignancies occur on top of liver cirrhosis.

The main risk factors for cirrhosis are chronic hepatitis B (HBV) and hepatitis C viruses (HCV) infection. Thus, screening of high-risk patients using ultrasound examination at 3-6 month intervals for early $\mathrm{HCC}$ diagnosis is essential in cirrhotic patients. This could permit early intervention, and possible curative treatment would be applied [9] .

This study aimed to assess the diagnostic value of serum leptin as a tumor marker in hepatocellular carcinoma. Our study obtained samples from 180 patients who were divided into: 60 patients in Group 1 (46 males and 14 females), 60 patients in Group 2 (42 males and 18 females), 30 patients in Group 3 (18 males and 12 females) and 30 control patients (16 males and 14 females). There were no significant differences between the studied groups regarding age and sex.

In the present study, treated and untreated HCC patients and patients with end-stage CLD without HCC had significantly higher serum leptin levels than healthy controls. This result was in agreement with Wang and Lin [10], who found that serum leptin levels were significantly higher in patients with cirrhosis and HCC patients than in healthy controls.

Also, this is in agreement with Bolukbas et al. [11], who found a significant increase in serum leptin levels in patients with end-stage liver diseases, where posthepatitis cirrhotic patients and healthy controls were enrolled in their study. They stated that serum leptin levels were significantly higher in patients with advanced liver disease when compared to healthy controls. This could be explained by the possible role of Leptin in HCC proliferation and invasion.

In contrast to these results, Ataseven et al. [12], on their study on patients with cirrhosis and patients with HCC, found significantly lower serum leptin levels in patients with cirrhosis and $\mathrm{HCC}$ when compared to healthy subjects; nonetheless, the etiology of liver cirrhosis in Egyptian patients differ from their study.

In the present study, serum leptin levels were significantly higher in HCC patients, either untreated or treated compared to end-stage CLD patients without HCC.

Sadik et al. [13] agreed with these results as regards increased serum leptin level in HCC patients. On the other hand, their study disagree as regards increased serum leptin levels in patients with cirrhosis without HCC. Their study showed that serum leptin level was significantly high in HCC patients only, and it was normal in both cirrhosis without $\mathrm{HCC}$ and in healthy control group with no significant difference between the two groups.

In this present study, serum leptin levels are significantly higher in untreated $\mathrm{HCC}$ than in treated HCC. This is in agreement with Miyahara et al. [14], who evaluated the predicted role of serum leptin as a biomarker for Sorafenib treatment effects in patients with HCC. They found highly significant levels of serum leptin at the baseline when correlated with the poor effects of Sorafenib treatment in patients with HCC. Thus, serum leptin could be used as a tool in the follow-up of HCC patients after treatment to detect any HCC recurrence.

Alpha-Fetoprotein (AFP) has been used to screen for HCC in liver cirrhosis; nonetheless, its value is not always increased in HCC patients, and the relation between its value and the outcome of HCC is still controversial. Furthermore, the ideal tool for detection of recurrence and propagation is not yet available. Thus, a more reliable tool that can predict the outcome, evaluate treatment response, and follow-up in HCC patients is required [15].

In the present study, serum leptin had the ability to differentiate between patients with CLD with $\mathrm{HCC}$ and without $\mathrm{HCC}$ at cutoff $>3.5 \mathrm{ng} / \mathrm{ml}$ with sensitivity $85 \%$ and specificity $80 \%$ however, AFP 
remains superior to it in this differentiation by cut off $>16 \mathrm{ng} / \mathrm{ml}$ with sensitivity $98.3 \%$ and specificity 93.3\%. This agrees with Ehab et al. [15], who found a significantly higher AFP level in HCC patients as compared to control $(p<0.001)$. Nevertheless, these results disagree with Heimbach et al. [16] who considered AFP as a poor tumor marker for diagnosing HCC due to its low sensitivity.

Furthermore, AFP levels have a significant difference in the 1 st group (untreated HCC patients) versus the 2 nd group (treated HCC patients) with cut off value $>72 \mathrm{ng} / \mathrm{ml}$, sensitivity $=96.7 \%$, specificity $=90 \%$ because its levels were significantly decreased after treatment. Serum leptin levels showed superior differentiation between treated and untreated groups of patients with $\mathrm{HCC}$ as at cutoff $>20 \mathrm{ng} / \mathrm{ml}$ with sensitivity $93.3 \%$ and specificity $93.3 \%$; thus, serum leptin was more specific than AFP in differentiation of treated and untreated HCC. Consequently, Leptin can be used in the follow-up of HCC after treatment for early detection of recurrence.

The limitations of the present study were the small sample size; thus, further prospective, welldesigned studies on the role and specific mechanisms of this hormone in patients with HCC on larger number of patients with other types of liver diseases predisposing to HCC as NAFLD or HBV are required to assess the diagnostic and prognostic value of serum leptin in those patients.

In addition, more studies are needed that can correlate the relation between serum AFP and serum leptin levels in patients during the different stages since their diagnosis as chronic liver disease patients and their progression till the development of HCC. Serial measurements of serum levels of both markers may be beneficial to estimate and assess the validity and benefit of serum leptin and its superiority upon serum AFP in the diagnosis, prognosis of HCC, and the effect of treatment on its serum levels.

\section{Conclusion:}

We concluded from this study that serum leptin had a good sensitivity and specificity as a tumor marker for diagnosis of HCC in patients at high risk to develop HCC as cirrhotic patients. It may be helpful to combine the use of serum leptin and serum AFP in the surveillance of cirrhotic patients for early diagnosis of HCC.

In addition to this diagnostic value, serum leptin is reduced in HCC patients treated with locoregional therapy, and this, in addition to AFP, may be helpful in the prognosis to follow-up treated HCC patients to predict any HCC recurrence.

\section{References}

1- JIM UM KIM, SHARIFF M., CROSSEU M., ROMERO G., HOLMES E., et al.: Hepatocellular carcinoma: Review of disease and tumour biomarkers. World Journal of Hepatology, 8 (10): 471-84, 2016.

2- WIEGAND J. and BERG T.: The Etiology, Diagnosis and prevention of Liver cirrhosis. Dtsch. Arztebl. Int., 110 (6): 85-91, 2013.

3- RAN XU ZHU, WAI KAY SETO, CHING-LUNG LAI and MAN-FUNG YUEN: Epidemiology of Hepatocellular carcinoma in the Asia-pacific region. Gut. and liver, 10 (3): 332-9, 2016.

4- SINGAL A., VOLK M.L., WALJEE A., SALGIA R., HIGGINS P., et al.: Meta-analysis: Surveillance with ultrasound for early-stage hepatocellular carcinoma in patients with cirrhosis. Aliment. Pharmacol. Ther., 30 (1): 37-47, 2009.

5- YU S.J.: A concise review of updated guidelines regarding the management of hepatocellular carcinoma around the world: 2010-2016. Clin. Mol. Hepatol., 22 (1): 7-17, 2016.

6- DALAMAGA M., CHOU S.H. and SHIELDS K.: Leptin at the intersection of neuroendocrinology and metabolism: Current evidence and therapeutic perspectives. Cell metabolism, 18 (1): 29-42, 2013.

7- ALEFFI S., PETRAI I., BERTOLANI C., et al.: Upregulation of proinflammatory and proangiogenic cytokines by leptin in human hepatic stellate cells. Hepatology, 42 : 1339-48, 2005.

8- DENG T., LYON C.J., BERGIN S., et al.: Obesity Inflammation, and Cancer. Annu. Rev. Pathol., 11: 421-49, 2016.

9- YAO F.Y.: Should surveillance for hepatocellular carcinoma be increased in patients with cirrhosis and small liver nodules? Nature Clin. Pract. Gastroenterol. Hepatol. 3: 544-5, 2006.

10- WANG Y.Y. and LIN S.Y.: Leptin in relation to hepatocellular carcinoma in patients with liver cirrhosis. Horm. Res., 60: 185-90, 2003.

11-BOLUKBAS F.F., BOLUKBAS C., HOROZ M., GUMUS M., ERDOGAN M., et al.: Child-Pugh classification dependent alterations in serum leptin levels among cirrhotic patients: A case controlled study. BMC Gastroenterology, 4: 23-10.1186/1471-230X-4-23, 2004.

12- ATASEVEN H., BAHCECIOGLU I.H., KUZU N., YALNIZ M., CELEBI S., et al.: The levels of ghrelin, leptin, TNF-a, and IL-6 in liver cirrhosis and hepatocellular carcinoma due to HBV and HDV infection. ediators of Inflammation, (4): 78380, 2006.

13- SADIK N.A., AHMED A. and AHMED S.: The significance of serum levels of adiponectin, leptin, and hyaluronic acid in hepatocellular carcinoma of cirrhotic and noncirrhotic patients. Hum. Exp. Toxicol., 31: 311-21, 2012. 
14- MIYAHARA K., NOUSO K., TOMODA T., et al.: Predicting the treatment effect of sorafenib using serum angiogenesis markers in patients with hepatocellular carcinoma J. Gastroenterol. Hepatol., 26: 1604-11, 2011.

15- EHAB M. ALI, TAREK M. MOHAMED, SAHAR S. BESSA, THORIA DIAB and HALA A. KARAM: SE-
RUM LEPTIN LEVEL AND HEPATOCELLULAR CARCINOMA. International Journal of Advancements in Research \& Technology, (7): 85-101, 2018.

16- HEIMBACH J.K., KULIK L.M., FINN R.S., et al.: AASLD guidelines for the treatment of hepatocellular carcinoma. Hepatology, 67: 358-80, 2018.

\section{تقييم دور اللبتين فى تشخيص ومتابعه ورم سرطان الكبد فى مرضى التليف الكبلى فئى وتئي}

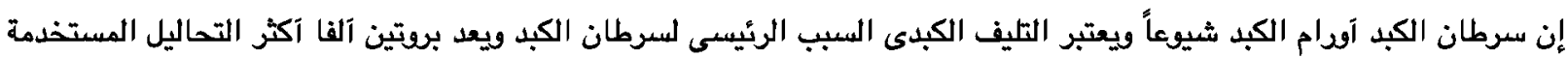

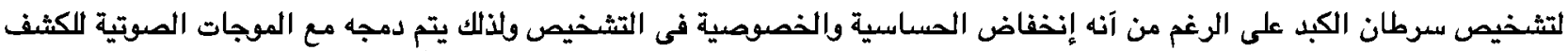

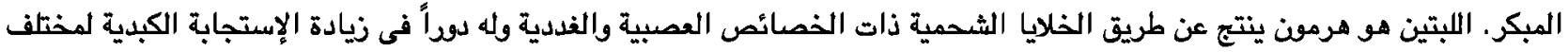

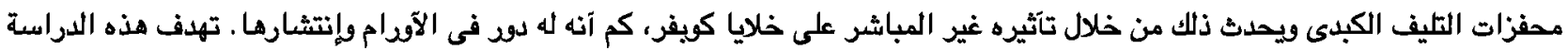

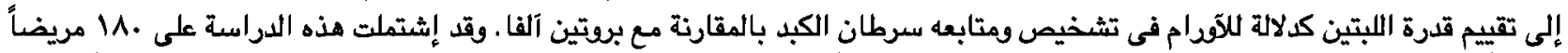

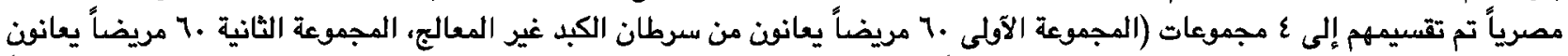

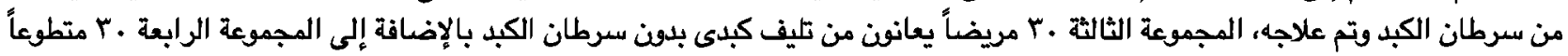

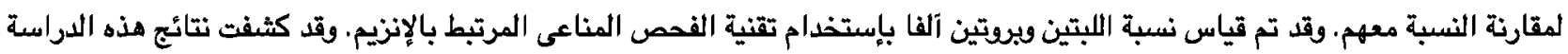

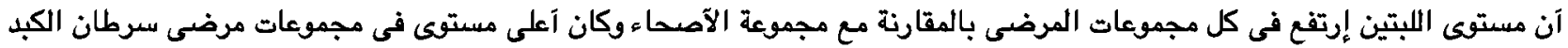

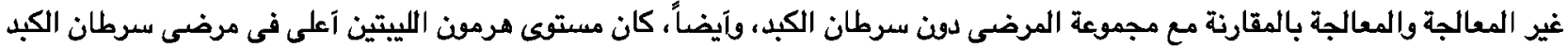

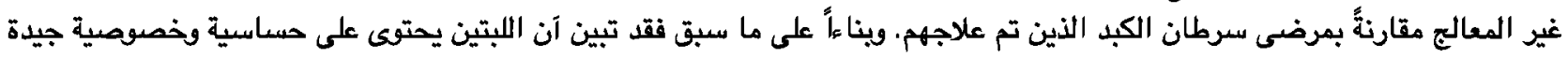

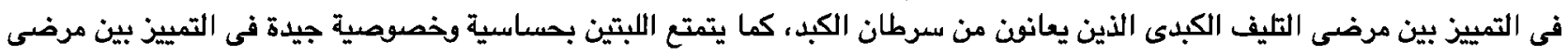

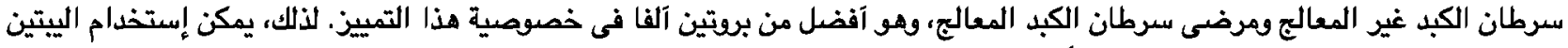

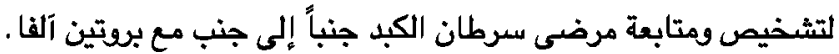

